\title{
EFFECTS OF MASSIVE OVERDOSE OF EPIDURAL MORPHINE SULPHATE
}

\author{
Pamela J. Masoud and Cloid D. Green
}

\begin{abstract}
A postoperative patient injected with epidural morphine, $60 \mathrm{mg}$, developed transient left bundle branch block and somnolence. The overdose was effectively treated with a continuous naloxone infusion for 19 hours. Analgesia persisted for an additional 19.5 hours. There was no evidence of sympathetic blockade or narcotic related neurotoxicity.
\end{abstract}

KEY WORDS: ANALGESIA, epidural morphine; COMPLICATIONS, epidural morphine overdose.

EPIDURAL MORPHINE appears to be an effective analgesic for most patients suffering from acute or chronic pain. It is especially appealing for patients with both compromised pulmonary function and a history of alcohol abuse and hepatic cirrhosis. In one such patient, however, we encountered a massive overdose and some unusual after effects from previously unreported complication.

\section{CASE REPORT}

A 58-year-old man underwent a right upper pulmonary lobectomy for a malignant nodule. Past medical history included an uncomplicated myocardial infarction 13 years earlier, chronic alcoholism until six months previously, and smoking in excess of "60 pack years." At admission his only medication was disulfuram $250 \mathrm{mg} /$ day. He weighed $67 \mathrm{~kg}$. Preoperative laboratory studies and liver function studies were normal. Pulmonary function tests revealed vital capacity of 4.3 litres: FEV 1 absolute of 2.1 litres ( 48 per cent); maximum voluntary ventilation of 97 per cent. Arterial blood gases (ABG's) were: $\mathrm{PaO}_{2} 9.4 \mathrm{kPa}(70.5 \mathrm{mmHg}) ; \mathrm{Paco}_{2} 5.7 \mathrm{kPa}$ (43 mmHg); $\left[\mathrm{H}^{+}\right] \mathrm{a} 37.15 \mathrm{nmol} / 1(\mathrm{pH} 7.43)$. The preoperative electrocardiogram showed the following measurements: PR 0.20; QRS 0.08; QT 0.38 , at a rate of 75 . It was interpreted as showing possible old anteroseptal infarct, left

Pamela J. Masoud, M.D.*, Cloid D. Green, M.D., Veterans Administration Medical Center, Omaha, Nebraska. ${ }^{1,2}$

*Corresponding Author's present address: Pamela J. Masoud, M.D., Department of Anesthesiology \& Critical Care Medicine, School of Medicine, Johns Hopkins University, Baltimore, MD 21205, U.S.A. anterior hemiblock and left axis deviation in the front plane at -40 to -60 degrees (Figure 1 ).

Preoperatively the patient chose the epidural administration of morphine for postoperative pain relief through a catheter that would be placed during operation at $T_{11}-T_{12}$ using the "loss of resistance" method. Preoperative medication consisted of morphine sulphate $5 \mathrm{mg}$ and droperidol $5 \mathrm{mg}$ intravenously. General anaesthesia was induced and maintained with enflurane, nitrous oxide and oxygen for three hours. When the patient had been extubated and awake for 45 minutes and complained of severe incisional pain, chloroprocaine three per cent $(1 \mathrm{ml})$ was injected to rule our intrathecal catheter placement. Three minutes later, a solution labelled as morphine sulphate $6 \mathrm{mg}$ in distilled water $(15 \mathrm{ml})$ was injected into the epidural space. Fifteen minutes after epidural injection, the psychogalvanic skin reflex (PGR) was tested and found intact. Thirty minutes after the epidural injection, the anaesthetist (PJM) was summoned because the modified $\mathrm{V}_{5}$ lead on the electrocardiogram (EKG) monitor showed

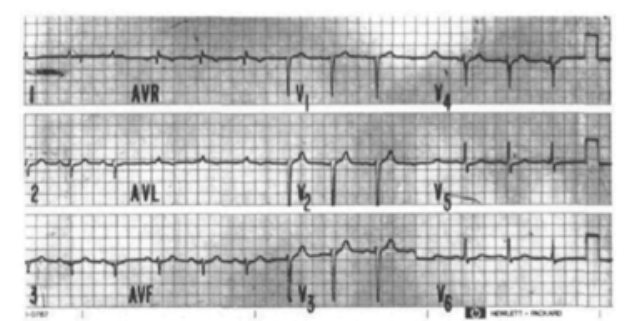

FIGURE 1 Preoperative electrocardiogram was interpreted as showing left axis deviation, left anterior hemiblock and possible old anteroseptal infarct.

Can. Anaesth. Soc. J., vol. 29, no. 4, July 1982 
periods of severe ST segment depression (Figure 2). When questioned, the patient denied pain in the chest, mandible, or left arm. He also denied dyspnoea. Upon request he breathed deeply and coughed. The ST segment pattern reverted to normal on the monitor tracing. Fifteen minutes later, 45 minutes after epidural injections, ST segment depression recurred and was unresponsive to coughing. It was noticed that the respiratory rate had decreased from 28 to 16 breaths per minute and that the patient was quiet but responsive to verbal stimuli.

A postoperative chest $x$-ray was compatible with an uncomplicated thoractomy. Blood was drawn for ABG determination and a 12-lead EKG completed. The EKG* showed sinus thythm, left bundle branch block, with a rate of 75. The patient's temperature was nomal and his blood pressure was within 10 torr of preoperative values. At that moment an urgent telephone call from Pharmacy apologetically informed us that an error in weighing the morphine powder had occurred, in that they had weighed and put in solution 10 times the amount requested. Thus the patient had received morphine sulphate $60 \mathrm{mg}$ epidurally. Accordingly naloxone $0.4 \mathrm{mg}$ was injected intravenously into a now somnolent patient, approximately 55 minutes after epidural injection. The first visible change in the patient's status occurred after five minutes, when the heart rate increased from 80 to 98 and the EKG tracings suddenly reverted to the patient's preoperative pattem and remained stable. Ten minutes after naloxone the patient was alert and talkative. He denied pain or difficulty in breathing. At 45 minute intervals, naloxone was injected intravenously after observing slight decreases in respiratory rate (see accompanying graph). Within five minutes after the third injection of naloxone, the patient began complaining bitterly of pain which lasted for 20 minutes. During that time the patient experienced periods of bigeminy from unifocal premature ventricular contractions. The PVC's ceased when the pain disappeared. Forty-five minutes after this episode a naloxone infusion $(0.8 \mathrm{mg} /$ $500 \mathrm{ml} \mathrm{D} 5 / \mathrm{W})$ was started at $0.08 \mathrm{mg} /$ hour $(1.2$ $\mu \mathrm{g} \cdot \mathrm{kg}^{-1} / \mathrm{hr}$ ) and increased to $0,128 \mathrm{mg} / \mathrm{hour}$ $\left(1.9 \mu \mathrm{g}^{\mathrm{kg}} \mathrm{g}^{-1} / \mathrm{hr}\right.$ ). The rate was adjusted according to respiratory rate and the results of $A B G$ 's (Figure 3). The epidural catheter was removed

*The 12-lead electrocardiogram was mounted, read, and subsequently lost. Fortunately, tracings of the three standard and augmented limb leads were recovered.

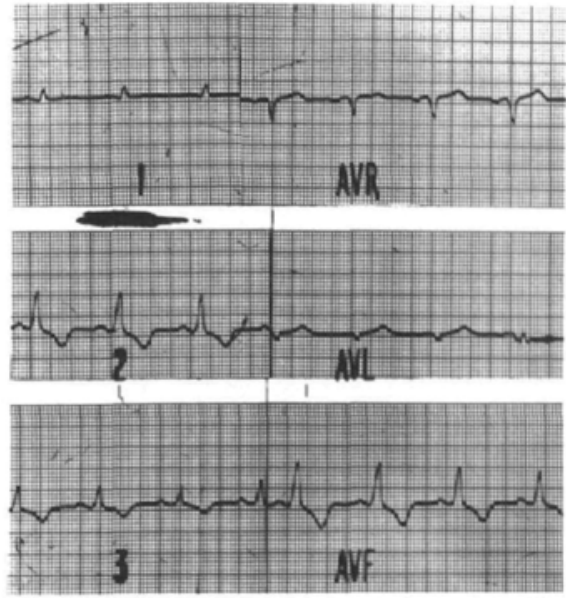

FtGURE 2 Postoperative electrocardiogram 45 minutes after epidural morphine injection was interpreted as showing left bundle branch block.

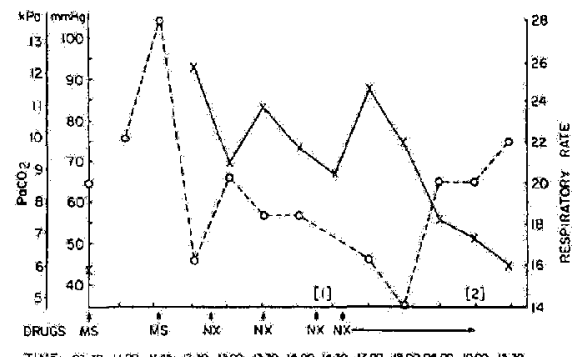

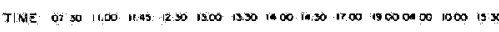

FIGURE 3 Changes in respiratory rate and $\mathrm{PaCO}_{2}$ after epidural morphine sulphate $60 \mathrm{mg}$.

$\mathrm{X}=$ Pacon.

$\mathrm{O}=$ Respiratory Rate.

[1] = Produced severe pain \& PVC's.

$[2]=$ Continuous infusion discontinued after the onset of pain.

The morphine sulphate (MS) administered at 0730 was $5 \mathrm{mg} \mathrm{IV}$, and at 1145 was $60 \mathrm{mg}$ epidural.

The naloxone (NX) administered at 1245, 1330, and 1415 was $0.4 \mathrm{mg}$ IV. At 1500 a continuous naloxone infusion at $0.08 \mathrm{mg} / \mathrm{hr}$ was started and increased to $0.128 \mathrm{mg} / \mathrm{hr}$.

and the patient was transferred to intensive care. At the time of transfer, one hour after naloxone infusion was started, the patient awoke quickly when verbally stimulated but when "resting", slept deeply.

$A B G$ 's were checked repeatedly during the night. By 10 am the following morning the patient complained of continuous pain and the 
infustion was discontinued, whereon analgesia again developed and persisted for an additional 19.5 hours. Vital signs and EKG tracings remained stable. Haemoglobin and electrolytes were normal. A new chest $x$-ray showed right lower lobe atelectasis, which resolved after vigorous chest physiotherapy. A neurological examination by a staff neurologist 24 hours after the epidural injection revealed no abnormalities. $A B G$ 's reverted to preoperative levels on the second postoperativeday. The rest of the hospital course was uneventful. A repeat EKG one month later, showed no interval change from the preoperative EKG.

\section{Discussion}

The large dose of morphine sulphate $(0.9$ $\mathrm{mg} \cdot \mathrm{kg}^{-1}$ ) administered epidurally $(12 \mathrm{mg} / \mathrm{min})$ had remarkably little effect on blood pressure and heart rate. The lack of haemodynamic effects with epidural overdose corroborates Lowenstein's study ${ }^{l}$ on patients subjech : to intravenous morphine $0.5-1.0 \mathrm{mg} \cdot \mathrm{kg}^{-1}$, at a rate of $10 \mathrm{mg} / \mathrm{min}$. In his study, intravenous morphine also had minimal effects on systemic blood pressure and heart rate.

Electrocardiographic effects, which included intermittent left bundle branch block 30 minutes after injection and somnolence 45 minutes after injection were the major complications of the overdose. The left bundle branch block may have been a complex haemodynamic result of the epidural morphine and attending hypercarbia. Most likely the left bundle branch block was also rate related ${ }^{2}$ and hence did not recur when the $\mathrm{PacO}_{2}$ rose to $11.4 \mathrm{kPa}$ (86 torr) at 1700 because the heart rate was now maintained at 90-92 instead of $78-80$ beats/minute.

Carefully documented time intervals occurred between the onset of left bundle branch block and somnolence ( 15 minutes) and between reversal of left bundle branch block and awakening ( 5 minutes). Cousins, et al. ${ }^{3}$ noted that after pethidine $100 \mathrm{mg}$ epidurally, blood concentrations approached "analgesic" levels after 30-40 minutes, producing mild sedation. The onset of significant sedation also occurred 40-45 minutes after epidural injection in our patient in the presence of normal blood pressure and heart rate. This suggests the presence of a greater sensitivity of the respiratory center to an overdose and less effect on the cardiovascular center until hypoxia and apnoea intervene.

Reversal of epidural morphine with inter- mittent intravenous naloxone was predictable in dose required $(\mathrm{mg} / \mathrm{kg})^{4}$ and time interval between repeat injections. ${ }^{5}$ The resulting complication of temporary loss of analgesia in retrospect was also predictable. An effective method of morphine antagonism was a continuous naloxone infusion of $1.9 \mu \mathrm{g} \cdot \mathrm{kg}^{-1} / \mathrm{hr}$. The patient was analgesic for 19 hours, yet awake with a steadily decreasing $\mathrm{Paco}_{2}$ and without recurrence of left bundle branch block.

It could be postulated that epidural morphine caused a sympathetic blockade. However, 15 minutes after injection and seven minutes after the patient became pain free, the psychogalvanic skin reflex (PGR) ${ }^{6}$ was intact, indicating that no sympathetic blockade had occurred at that time. We neglected to repeat it because we assumed that sympathetic fibers would be blocked before pain fibers if they were to be affected. Cousins, et al. ${ }^{3}$ found that sympathetic function was intact after epidural pethidine as evidenced by a normal cobalt blue sweat test and lack of postural hypotension. Many observations have been made of the PGR on other patients having injections of morphine sulphate 3-6 mg epidurally. If sympathetic blockade did occur in this patient, it must have occurred later and may have been dose related.

Twenty-four hours after epidural injection, when analgesia returned after naloxone infusion, the neurologist evaluated the patient's neurological function. He tested orientation, motor function, proprioception, sensation to light touch and pinprick, and deep tendon reflexes. The patient was judged to have normal neurological function. Concern for neurological function arose from our previous VA study ${ }^{7}$ that neurotoxicity of epidural narcotics might be dose related.

\section{SUMMary}

In summary, a patient was rapidly injected by error with morphine sulphate $60 \mathrm{mg}$ epidurally. Left bundle branch block and ST segment depression signalled a problem. Respiratory depression occured 15 minutes later. Sympathetic blockade of the lower extremities was not detected. Injections of naloxone reversed the left bundle branch block and respiratory depression but appeared to be cumulative and resulted in severe pain. A continuous naloxone infusion was effectively titrated to minimize respiratory depression for 19 hours without reversing analgesia. Twenty-four hours after epidural in- 
jection, the neurological examination was normal. Epidural morphine analgesia persisted for approximately 38.5 hours.

\section{ACKNOWLEDGEMENTS}

The authors gratefully acknowledge Mark C. Rogers, M.D., Department of Anesthesiology \& Critical Care Medicine, for review of this manuscript, and Jason T. Ohr, M.D., Department of Neurology, for neurological evaluation for this patient. We also thank James Shum, R.N., and Marilyn Piper, R.N., Recovery Room, for their vigilance and meticulous care of this patient, and Janet Wolfe for her secretarial assistance.

\section{REFERENCES}

1. Lowenstein E., Hollowell, P., Levin, F.H et al. Cardiovascular response to large doses of intravenous morphine in man. N. Eng. J. Med. 281: 1389 (1969)

2. Shearn, M.A. \& Rytand, D.A. Intermittent bundle branch block: observations with special reference to the critical heart rate. Arch. Interm. Med. 91: 448 (1953)

3. Cousins, M.H., Mather, L.E., GlynN, C.J. et al. Selective spinal analgesia. Lancet $1: 1141$, (May 26, 1979).

4. GUPTA, P.K. \& DUNDEE, J.W. Morphine combined with doxopram or naloxone. Anaesthesia 29:3 (1974).

5. Evans, J.M., HogG, M.I.J., LunN, J.N., et al. Degree and duration of reversal by naloxone of effects of morphine in conscious subjects. $\mathrm{Br}$. Med. J. 2: 589 (1974).

6. LEWIS, L.W. Evaluation of sympathetic activity following chemical or surgical sympathectomy. Anesth. Analg. 34: 334 (1955).

7. Masoud, P.J. \& GREEN, C.D. Transient neurologic effects after epidural morphine. Anesth. Analg. 60: 540 (1981).

\section{RÉSUME}

Un malade qui venait subir une résection lobaire supérieure droite ayant reçu par erreur une dose de $60 \mathrm{mg}$ de morphine par voie péridurale (à l'espace $T_{11}-T_{12}$ ) a présenté 30 minutes après l'injection un bloc de branche gauche avec sous-décalage du segment ST; une dépression respiratoire apparut 15 minutes plus tard. La surdose morphinique put être traitée de façon efficace avec une perfusion de naloxone administrée au cours des 19 heures suivantes, à une dosage permettant le maintien de l'analgésie post-opératoire. Celle-ci persista encore pendant 19.5 heures après l'arrêt de la perfusion de naloxone. Le tout se déroula sans signe de blocage sympathique au niveau des membres inférieurs. Vingt-quatre heures après l'accident, l'examen neurologique était normal. 